\title{
Activating Older Unemployed Individuals: A Case Study of Online Job Search Peer Groups
}

\author{
Irina Sigler \\ University of Ulm \\ irina.sigler@uni-ulm.de
}

\begin{abstract}
Improving re-employment chances for older unemployed individuals is a priority for policymakers around the world. While digital job search interventions have proven beneficial for young and middle-aged individuals, their value to support re-employment at older ages has not been investigated so far. To shed light on the potential of digital interventions to assist older unemployed individuals, we analyze a unique data set from a randomized field study introducing online job search peer groups at the Federal Employment Agency in Germany. Results suggest that online peer groups offer substantial added value compared with traditional job search counseling. Participation in online peer groups significantly increases the number of job applications and job interview invitations. We show that older unemployed individuals are accessible for digital job search assistance and identify online peer groups as a powerful intervention to activate this target group.
\end{abstract}

\section{Introduction}

The loss of employment is a traumatic event for anyone, but the consequences are especially devastating for people above the age of 50. Compared to younger people, older individuals suffer stronger financial and psychological losses related to unemployment $[1,2]$. This age group has lower chances of returning to work $[3,4]$, which often leads to long-term unemployment and an early labor market exit [5]. The cumulative effect of these individual disasters is a tremendous societal challenge, as the sustainability of public finances and economic growth is threatened by unemployment in a rapidly growing sector of the worldwide population $[5,6]$.

To address this issue, research and policy have developed a wide range of active labor market programs to assist older unemployed individuals. Examples include training, job-search counseling, and subsidized employment $[5,7,8]$. Still, these programs are often cost-intensive [5,7] and their effectiveness is mixed $[7,8,9]$. Since these programs are mostly delivered inperson, the societal value of Information and Communications Technology (ICT) to improve re-employment chances of older unemployed individuals remains untapped [5,9].

While initial research testifies to the benefits of ICT for finding employment in young and middle-aged individuals [10,11, 12, 13, 14, 15], little is known about the effectiveness for older unemployed people. To gain insights into the impact of ICT on this target group, we collected and analyzed a unique data set from a randomized field study introducing a digital labor market intervention for unemployed individuals above the age of 50 at the Federal Employment Agency in Germany between February 2019 and March 2020. The intervention consisted of online peer groups, which build on the social support of individuals who share a common issue or need [16] and connect peers in a discussion forum facilitated by digital media [17, 18]. Online peer groups have previously been shown to be effective across a wide range of settings, such as fighting addiction [19], fostering education [20], and even improving re-employment in young job seekers [15].

To the best of our knowledge, our case study is the first to provide quantitative data on the effectiveness of participating in an online peer group for older unemployed individuals. Participating in online peer groups significantly increased job search activities, including job applications and job interviews, as compared to a control group. Furthermore, our results demonstrate that older unemployed individuals actively use digital approaches to find employment. Our contribution to research and practice is twofold. We identify online peer groups as a powerful measure to activate older unemployed individuals. Second, our research provides evidence that older unemployed individuals are responsive to targeted-group-based digital services in the context of job search.

The research presented in this paper is structured as follows. Section 2 illustrates the theoretical background, 
followed by a description of the research methodology in Section 3. After demonstrating our results in Section 4 , we discuss the implications of our findings in Section 5. In Section 6, we reflect on the limitations of our study and provide directions for further research. A summary concludes our paper in Section 7.

\section{Theoretical Background}

\subsection{Problem Context}

The consequences of unemployment at a more advanced age are severe on both the individual and the societal level. Job loss has a particularly devastating effect on older individuals who suffer tremendous financial and psychological losses related to unemployment $[1,2]$. As older unemployed individuals have comparatively weak chances of finding new employment $[3,4]$, job loss in this age group is often a prelude to long-term unemployment and early labor market exit [5].

While the definition of older individuals varies between different countries and regions [5], for this research we focus on individuals above the age of 50 . This group is shown to experience age-related workplace discrimination [21] and have lower chances of re-entering the labor market $[3,4]$.

Research and policy have developed a wide range of active labor market programs to help unemployed people re-enter the labor market $[5,7,8]$. To assess the effectiveness of these programs in improving the likelihood of employment, research suggests the following three indicators: increased job search behaviors, advanced job search skills, and high selfefficacy [9, 22, 23].

First, an increase in job search behaviors is associated with higher chances of re-entering the labor market [24]. Such behaviors constitute a set of careerrelated activities, such as submitting applications or networking [25]. An improvement in job search behavior is often operationalized as job-search intensity, thus, devoting more time and effort to the job search $[22,23]$. Job search intensity declines with age [26] and partly explains lower re-employment chances amongst older workers [4]. Changing job search behavior is therefore a promising means for counteracting these trends. Behavioral learning theory suggests social reinforcement and supervision can induce behavioral change and increase job seeking activities [9].

Second, good job search skills are related to higher job search success and are often the immediate outcomes of active labor market programs [9, 22, 23]. More specifically, these include both the knowledge and the ability to conduct a job search effectively, e.g., CV writing skills, interview skills, developing a clear job search strategy $[9,22,23]$. As older individuals are assumed to have a less developed skillset for the job search in general $[3,9]$ and digital job search tools in particular $[3,5]$, improving job search skills is particularly important for this target group.

Finally, the theory of planned behavior suggests that positive attitude and perceived behavioral control impact behavioral performance. In the context of job search, this dimension is often operationalized by increased self-efficacy, i.e., the belief of having the capacity to conduct actions to produce a desired outcome [27], which is closely associated with selfassessed job search skills [9]. Prior research shows that high self-efficacy improves chances of re-entering the labor market [27], as it positively influences job search behavior [9]. As self-efficacy declines with age, active labor market programs designed for older job seekers should aim to improve this dimension [28].

\subsection{Digital Labor Market Interventions}

"Today, fast-evolving technologies have a potential to transform the traditional way of doing things across all functions and domains of government" [29, p. 29]. However, most job search assistance is delivered inperson $[5,9]$, and the potential of digital technology to serve the unemployed population remains untapped $[5,9]$. In the context of re-employment, digital services might be more efficient as they help to reduce costs, enable scaling, and eliminate time and space constraints $[14,30]$. Even more importantly, digital services might be more effective in helping unemployed people reenter the labor market compared to analog job search assistance.

There is initial evidence testifying to the benefits of ICT for finding employment in young and middle-aged individuals. Access to high-speed internet has been shown to improve re-employment rates in Germany [10]. In addition, online job search raised employment chances among young employment seekers in the U.S. by $25 \%$ [11]. Furthermore, engaging in social networks increased the number of job leads and interviews in educated, white-collared workers with an average age of 39 , who lost their jobs at large organizations across the U.S. during 2010 [12]. Research also suggests that technology-mediated job search interventions can improve labor market prospects. The introduction of a mobile application facilitated the job search and motivated young job seekers in German states, where youth unemployment was above the national average [13]. Also, digital job search assistance increased the number of job interviews in the U.K., for a group with a median age of 36 , almost half of them with a university degree [14]. 
However, little is known about the effectiveness of digital interventions for improving re-employment in older individuals. Contrary to conventional wisdom, initial research suggests that a large share of unemployed individuals above the age of 50 has access to and even desires more digital job search assistance [31]. Further, research suggests that digital media engagement helps older unemployed individuals to better cope with the psychological consequences of job loss. While an investigation of unemployed social media users showed that social media engagement improved well-being across age groups, the effect was especially prominent in older participants [32]. This is consistent with findings in other settings suggesting that digital engagement improves social connectedness in older individuals [33, 34].

Still, the evidence of digital interventions on reemployment indicators in older individuals remains vague. An Australian study analyzing the effects of an online application assistance found that it increased job finding rates among individuals aged 35-50; at the same time, the intervention did not improve outcomes for subjects above the age of 50. The authors argued that job seekers above the age of 50 might have a reduced ability to effectively navigate online resources [35]. Another explanation, demonstrated in research on offline job search interventions, might be the fact that older job seekers mostly benefit from targeted interventions $[9,36]$.

To date, to the best of our knowledge, no study exists that quantifies the impact of digital job search interventions to support re-employment at older ages. Against this backdrop, this study investigates the effect of online peer groups on indicators related to reemployment.

\subsection{Online Job Search Peer Groups}

Connecting older unemployed individuals via offline peer groups has been shown to increase employment in participants across a diverse range of different occupations (31\% manual or unskilled, $33 \%$ skilled or clerical, and $36 \%$ managerial or professional) [37]; replicated in a following study [38]. During the proliferation of digital media in the 1990s, online peer groups received increasing research attention [39]. Peer groups build on the social support of individuals who share a common issue or need [16]. The online version brings those individuals together in a forum facilitated by digital media $[17,18]$. The peers provide mutual support to each other by exchanging advice, information or empathy [40], and thereby foster a "change in the belief, attitude or behavior" [41, p. 138].

Online peer groups provide benefits to diverse age groups, including the elderly [42] and school-age students [15]. Also, they show positive societal impact across a wide range of settings, such as fighting addiction [19], fostering education [20], and even finding employment [15].

Online peer groups increase employment in pupils of middle schools, main schools, and comprehensive schools in Germany and improve attitude, intensity, and maturity of job seeking, thus providing an effective supplement to face-to-face career counseling [15]. In the context of unemployed individuals with complex barriers, such as mental health issues or addiction, effectiveness is less clear. On the one hand, participants in this German study appreciated the design features of the online peer group, e.g., mobile and anonymous communication [43], and showed positive tendencies along several indicators of successful employment, although none of the results were significant [43]. On the other hand, the results also showed a negative tendency for having a clear career strategy, suggesting a potentially distorting effect of participation in an online peer group [43].

Research to date has not investigated the effectiveness of participating in an online peer group in the older unemployed population. To gain insights into the potential of online peer groups to serve unemployed individuals above the age of 50, we analyze a unique data set from a randomized field study introducing online peer groups at the Federal Employment Agency in Germany.

\section{Research Methodology}

\subsection{Case Setting and Subjects}

We conducted our randomized field study in cooperation with the Federal Employment Agency in Germany (Bundesagentur für Arbeit). With 156 employment agencies, roughly 600 branch offices, and over 95,000 employees, the Federal Employment Agency is the largest provider of labor market services in Germany. Services include career counseling, employment placing, and financial support.

Between February 2019 and March 2020, a new digital service was introduced to assist labor market prospects for unemployed individuals above the age of 50. The case study was conducted in BadenWürttemberg, the third-largest state in Germany and home to a large automotive and mechanical engineering industry [44]. During the study, the region experienced slowed economic activity [45].

The digital service consisted of online peer groups that supplemented the traditional face-to-face counseling sessions. The peer groups were realized via the instant messaging client Riot.im based on the Matrix 
protocol. Each online peer group consisted of about 20 participants and a professional career counselor who acted as a moderator. In addition to facilitating the exchange of text messages, the application also supported document sharing, such as CVs and brochures for career events. All online peer groups had a total duration of three months and were deactivated afterwards; the last group was deactivated end of January 2020.

To measure the effectiveness of the online peer groups, we conducted a pre-test/post-test on both the treatment and the control group, following an established research design [15, 43]. The study consisted of three stages (see Figure 1 for an overview).

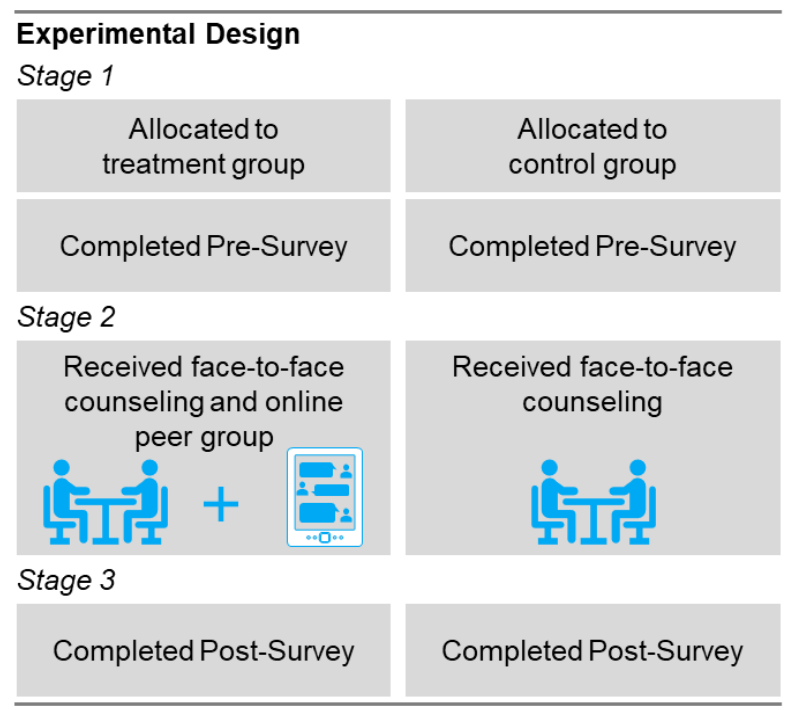

Figure 1. Experimental design

In stage 1, we assessed subjects for eligibility, briefly informed them about the study, randomly allocated them to the treatment and the control group, and requested that they complete a pre-survey. 267 subjects allocated to the treatment and 264 subjects allocated to the control group volunteered to participate and completed the pre-survey.

In stage 2, during three months, all subjects received traditional face-to-face counseling, while subjects in the treatment group also participated in online peer groups. Of the 267 subjects who completed the pre-survey, 205 participated in the online peer groups, and 62 decided to discontinue the project. All 264 subjects allocated to the control group received face-to-face counseling.

In stage 3 , we asked all participants to complete a post-survey. $61 \%$ of all subjects in the treatment and $47 \%$ of all subjects in the control group completed the post-survey. In the analysis, we only included those subjects who completed both surveys. Due to data quality issues, we had to exclude several subjects $(5 \%$ in the treatment group, $6 \%$ in the control group). In total, we collected 119 valid questionnaires for the treatment and 118 valid questionnaires for the control group.

Subjects in the randomized field study were sampled among unemployed individuals above the age of 50 (participants' age-span: 50-66) in seven employment agencies, including both rural and urban districts. Most subjects were priorly employed in clerical or professional positions $(82 \%)$, followed by workers $(13 \%)$, civil servants $(2 \%)$, and self-employed individuals $(2 \%)$. Participation in the experiment was entirely voluntary, with the requirement that all participants have sufficient German language skills to communicate via written messages effectively. Table 1 summarizes the demographics of our sample, based on data gathered from valid pre- and post-surveys.

\section{Table 1. Sample demographics}

\begin{tabular}{lr}
\hline Variable & N (Percentage) \\
\hline Gender & \\
Female & $101(43 \%)$ \\
Male & $136(57 \%)$ \\
Age & \\
$50-55$ & $81(34 \%)$ \\
$55-60$ & $92(39 \%)$ \\
$>60$ & $64(27 \%)$ \\
Education & \\
No school leaving certificate & $3(1 \%)$ \\
Lower secondary & $36(15 \%)$ \\
Intermediate secondary & $41(17 \%)$ \\
Upper secondary & $17(7 \%)$ \\
Vocational training & $59(25 \%)$ \\
University degree & $79(33 \%)$ \\
Not specified & $2(1 \%)$ \\
Unemployment duration & \\
$<3$ months & $10(4 \%)$ \\
3-6 months & $45(19 \%)$ \\
$6-12$ months & $74(31 \%)$ \\
$>12$ months & $108(46 \%)$ \\
\hline
\end{tabular}

Our analysis is based on two datasets: usage data and survey data. We collected usage data, i.e., all messages, including metadata such as participant identification code and timestamp. In total, 205 unemployed individuals and 11 counselors from 7 employment agencies, replaced by a colleague in case of absence, participated in 11 online peer groups. Second, we conducted pre- and post-surveys with all participants in the treatment and the control group. In the analysis, we only included those subjects who completed both surveys resulting in 119 valid 
questionnaires for the treatment group and 118 valid questionnaires for the control group. Participants chose to complete the survey in either a paper-based or online format. The tool "SoSci Survey" was used to collect the online version. All questions were provided in German, and no incentives were offered to respondents.

\subsection{Measurement}

To ensure reliability and validity of the measurements, we used indicators established by prior research to measure improvement in re-employment chances $[9,22,23]$. To operationalize improvement in job search behavior and self-assessed job search skills, we adopted established constructs from research on the effects of employment interventions in Germany [25]. As digital incompetence impedes job search in older individuals, we added an abbreviated assessment of digital competencies based on established questionnaires [46]. Finally, we used standard questionnaires to measure improvement in self-efficacy [47].

Except for constructs related to the dimension job search behavior, all constructs were measured using a Likert-type scale ranging from 1 ("strongly disagree") to 6 ("agree strongly"). When a construct was comprised of multiple items, we calculated the variable as the mean of the item's score. Table 2 provides an overview of the constructs per dimension, the number of items per construct and the items' scales.

Table 2. Overview on constructs measuring success with respect to employability

\begin{tabular}{|c|c|c|c|}
\hline Dimension & Construct & Items & Scale \\
\hline \multirow{2}{*}{$\begin{array}{l}\text { Job search } \\
\text { behavior }\end{array}$} & $\begin{array}{l}\text { Number of job } \\
\text { applications }\end{array}$ & 1 & $\begin{array}{c}\text { Free input on } \\
\text { number of } \\
\text { applications }\end{array}$ \\
\hline & $\begin{array}{l}\text { Number of } \\
\text { invitations to } \\
\text { job interviews }\end{array}$ & 1 & $\begin{array}{c}\text { Free input on } \\
\text { number of } \\
\text { invitations }\end{array}$ \\
\hline $\begin{array}{l}\text { Job search } \\
\text { skills }\end{array}$ & $\begin{array}{l}\text { Written } \\
\text { application } \\
\text { skills } \\
\text { Career strategy } \\
\text { and interview } \\
\text { skills }\end{array}$ & 6 & $\begin{array}{l}\text { 6-point } \\
\text { Likert-type } \\
\text { scale }\end{array}$ \\
\hline $\begin{array}{l}\text { Digital } \\
\text { competencies }\end{array}$ & $\begin{array}{l}\text { Information } \\
\text { processing } \\
\text { Communication } \\
\text { Safety } \\
\text { Problem solving }\end{array}$ & $\begin{array}{l}1 \\
3 \\
2 \\
2\end{array}$ & $\begin{array}{c}\text { 6-point } \\
\text { Likert-type } \\
\text { scale }\end{array}$ \\
\hline Self-efficacy & Self-efficacy & 10 & $\begin{array}{c}\text { 6-point } \\
\text { Likert-type } \\
\text { scale }\end{array}$ \\
\hline
\end{tabular}

The design of our questionnaire follows scientific guidelines to reduce response bias [48, 49]; thus, we selected an even-numbered Likert-type scale to prevent middle option bias [48].

The comprehensibility of the survey items was validated with professionals at the Federal Employment Agency and four Information Systems researchers.

\section{Results}

\subsection{Adoption of Online Peer Groups}

First, we determined whether and to what extent participants assigned to the treatment group utilized the digital service by analyzing usage data.

$83 \%$ of all participants in the treatment group wrote at least one message during the experiment's duration. The participants shared 2,390 messages between each other during the three months of treatment, excluding the messages shared by the professional counselors who acted as moderators (median number of messages in active participants $=8$ ).

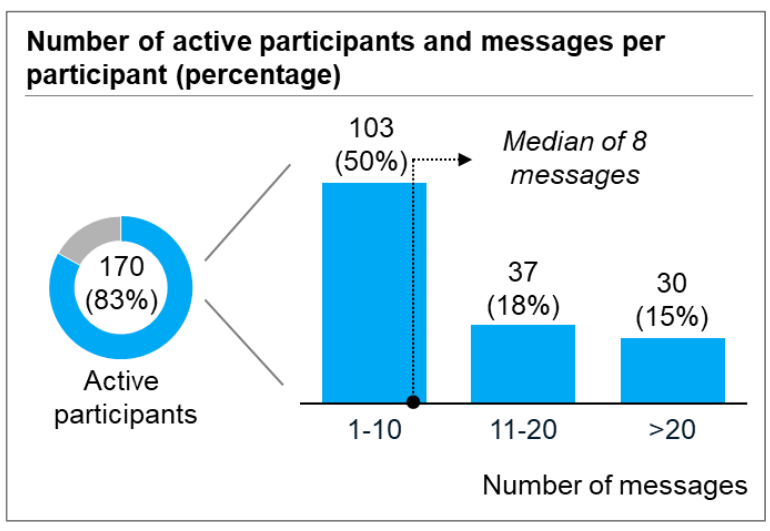

Figure 2. Adoption of online peer groups

\subsection{Effect of Online Peer Groups}

Comparability of subjects in the treatment and the control group is a prerequisite to attribute any significant difference between the groups to the experimental manipulation, i.e., the online peer groups. Therefore, we verified that the random assignment had indeed produced similar distributions in the treatment and the control group for potentially confounding characteristics such as gender, age, education, German language skills, marital status, children, unemployment duration, and previous occupation [3,4]. Chi-square analyses of these variables revealed no significant differences between the two groups at the beginning of the experiment. 
To evaluate the effect of the online peer-group based intervention, we first derived the differences in each construct per subject in the treatment and the control group. As a next step, we compared the distribution of differences in the control group against the distribution of differences in the treatment group. To investigate whether a significant difference exists in the development of the two groups, we applied MannWhitney $U$ tests for independent samples. For this research, a significant difference is defined at a p-value below 0.05 .

In what may be the most critical outcome of this study, our results show that job search behavior is positively affected by participating in an online job search peer group.

With respect to the number of job applications, we detect a significant between-group difference according to the Mann-Whitney U test statistic $(\mathrm{p}=0.036)$. The median number of job applications of the subjects in the control group does not change between the pre- and post-survey (median control group pre $=10$, median control group post $=10$ ). In contrast, the subjects in the treatment group show a striking positive difference, with a median of 10 job applications before the treatment and 14 job applications by the end of the three-month experimental period (see Figure 3).

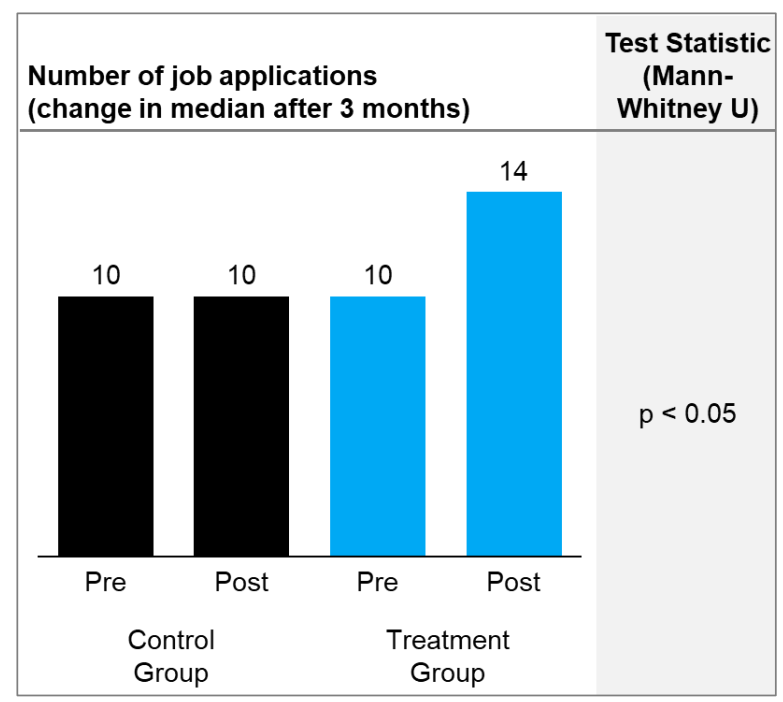

Figure 3. Development in job applications

We also observe that the number of job interview invitations is positively affected by participating in an online peer group (see Figure 4). The subjects in the treatment group show an increased number of invitations to job interviews as compared to control group subjects (Mann-Whitney $U$ test; $p=0.030$ ). Similar to the development in the number of job applications, the median number of invitations to job interviews does not change in the control group between the pre- and post-survey (median control group pre $=1$, median control group post $=1$ ). Surprisingly, the subjects in the treatment group show a prominent positive difference following the treatment period, with a median of 1 interview invitation before the treatment and 2 invitations afterwards.

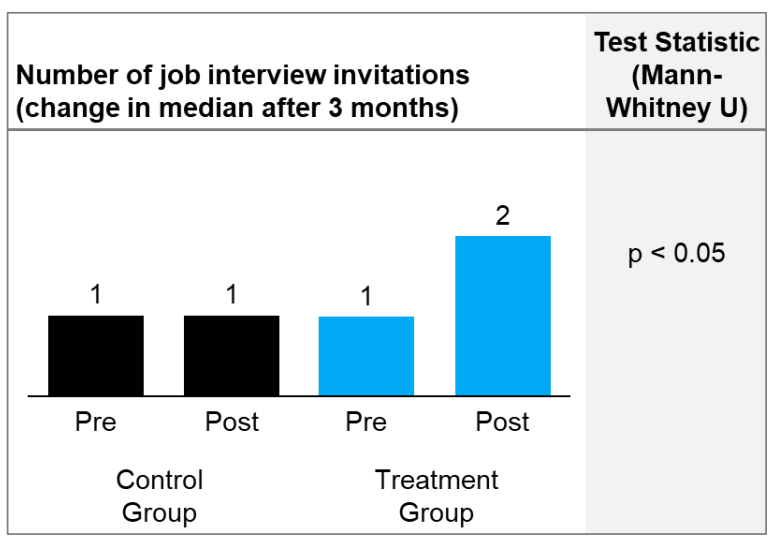

\section{Figure 4. Development in job interview invitations}

The treatment group and the control group show no significant difference regarding the development of selfassessed job search skills (see Table 3 ).

The mean scores for written application skills and career strategy and interview skills do not develop differently following the treatment period between the treatment group and the control group.

Also, subjects in the treatment group and the control group show no difference in the development along the following self-assessed digital skills: information processing, communication, safety, and problem solving (see Table 3).

Finally, there is no significant difference in selfefficacy development between the two groups (see Table 3). The mean self-efficacy scores of the treatment and the control group do not change after the treatment period. 
Table 3. Development in job search skills, digital competencies and self-efficacy

\begin{tabular}{|c|c|c|c|c|c|}
\hline $\begin{array}{l}\text { Dimension / } \\
\text { Construct } \\
\text { (6-point Likert-type }\end{array}$ & & $\begin{array}{l}\text { trol } \\
\text { up }\end{array}$ & $\begin{array}{r}\text { Tre: } \\
\mathbf{G} \\
(\mathrm{M}\end{array}$ & $\begin{array}{l}\text { ment } \\
\text { up } \\
\text { an) }\end{array}$ & $\begin{array}{c}\text { Test } \\
\text { Statistic } \\
\text { (Mann- } \\
\text { Whitney U) }\end{array}$ \\
\hline & Pre & Post & Pre & Post & \\
\hline Job search skills & & & & & \\
\hline $\begin{array}{l}\text { Written application } \\
\text { skills } \\
\text { Career strategy and } \\
\text { interview skills }\end{array}$ & 4.6 & 4.6 & 4.7 & 4.9 & $\begin{array}{c}\text { No } \\
\text { significant } \\
\text { difference }\end{array}$ \\
\hline $\begin{array}{l}\text { Digital } \\
\text { competencies }\end{array}$ & & & & & \\
\hline $\begin{array}{l}\text { Information } \\
\text { processing }\end{array}$ & 4.4 & 4.5 & 4.9 & 5.0 & \\
\hline Communication & 3.9 & 4.1 & 4.0 & 4.3 & $\begin{array}{l}\text { No } \\
\text { ant }\end{array}$ \\
\hline Safety & 5.1 & 5.2 & 5.3 & 5.5 & difference \\
\hline Problem solving & 4.7 & 4.9 & 5.1 & 5.3 & \\
\hline Self-efficacy & & & & & \\
\hline Self-efficacy & 4.3 & 4.3 & 4.5 & 4.5 & $\begin{array}{c}\text { No } \\
\text { significant } \\
\text { difference }\end{array}$ \\
\hline
\end{tabular}

\section{Discussion}

Our research is motivated by the societal challenge of fighting unemployment in older individuals. We investigate whether ICT can meet this challenge and serve to improve the re-employment chances of older job seekers. To this end, we analyzed a unique data set from a randomized field study of online peer groups for unemployed individuals above the age of 50, conducted in cooperation with the Federal Employment Agency in Germany. Our findings have three main implications for theory and practice.

First, our research provides strong evidence that online peer groups help activate older unemployed individuals. We observe a significant improvement in job search behaviors after participation in online peer groups when compared to a control group. The treatment group participants wrote more applications (change in median +4 ), and were invited to more job interviews (change in median +1 ) after the treatment. In contrast, the control group shows no improvement in either area. Our research suggests that the change in behaviors observed in offline peer groups [37, 38] can be replicated digitally for the older unemployed population. Also, we confirm that the increase in job search intensity observed in youths [15] can also be demonstrated in older job seekers. Evidence indicates that social support serves as a pathway to increase job search intensity in unemployed individuals above the age of $50[26,50]$. More specifically, this target group mainly benefits from support provided by unemployed friends, rather than other employed or retired friends or family members $[26,50]$. As online peer groups help to connect peers who share a common challenge or need, our research provides preliminary evidence that online peer groups serve as an effective means to build such relationships. The convenience and ubiquitous nature of mobile service delivery might have further facilitated the change in behaviors [51], as research on offline peer groups for older individuals reports a desire for more frequent exchanges with peers [38]. From a practical perspective, activating older job seekers is particularly crucial, as job search intensity declines with age [26] and partly explains lower re-employment chances for older job seekers [4]. In light of this challenge, we identify online peer groups as a powerful measure to increase job search intensity among the older unemployed population. Thus, our research is an initial step towards modernizing labor market services and suggests the adoption of digital peer-group based services in addition to face-to-face counseling.

Second, our results shed light on the limitations of online peer group interventions for older unemployed individuals. We observed no change in written application skills, interview and career strategy skills, digital competencies, and self-efficacy following participation in online peer groups. This contrasts with observations in other settings where online peer groups improved attitude and self-assessed skills $[15,52,53,54]$. Observations from offline peer groups might shed light on these findings. Older unemployed individuals show improvement in self-efficacy when specific learning assignments complement peer group participation [55]. Other evidence suggests that skill and self-efficacy development require additional components $[9,56]$, and that peer learning works best as a supplement to other training [57]. Our findings indicate that while peer groups serve the crucial goal of activating older unemployed individuals, additional interventions are needed to improve skills and selfefficacy.

Third, our results demonstrate that older unemployed individuals actively use digital career search assistance. About $83 \%$ of all subjects in the treatment group wrote at least one message, and about $33 \%$ even wrote over ten messages throughout the duration of the experiment. Thereby, older individuals participate almost as actively as youths in a similar employment-related peer group, which had a 100\% participation rate [15]. Further, the participation rate is strikingly high when compared to online peer groups in other settings [19] and large social health networks, 
where less than $25 \%$ of participants contribute more than one message [58]. The active participation in the online peer groups partly contests findings of an overrepresentation of older unemployed individuals among non-users of digital media [59] and the higher share of older people among "lurkers" in online support groups [60]. Thus, our findings are consistent with research suggesting that older unemployed individuals are accessible for digital assistance in job search [31]. The setting and design of the digital intervention, aimed explicitly at individuals above the age of 50, might serve as a potential reason for the strong participation. Research demonstrates that older job seekers mostly benefit from interventions specifically targeted to them $[9,36]$. Furthermore, the intervention design was informed by prior literature. The peer groups were implemented as localized and closed sub-networks [42], aiming at high usability and data protection standards identified as essential features for job seekers above 50 [31]. Our research provides evidence that older unemployed individuals are responsive to targetedgroup-based digital services in the context of job search.

\section{Limitations and Directions for Future Research}

Besides the highlighted research contributions presented in this paper, we acknowledge the limitations of this study that constitute interesting avenues for future research.

First, our data comes from a single case study in one country. Though we build on a rich dataset gathered from several online peer groups at different branch offices of the Federal Employment Agency in Germany, including both rural and urban areas, these findings may not be generalizable to other countries. Thus, we invite future research to investigate online peer groups for older unemployed individuals in other countries to shed light on the impact of cultural and regional differences and to substantiate our findings.

Second, we acknowledge that our initial sample of eligible participants may suffer from self-selection bias. We addressed this bias by the randomized allocation of the participants to the control and the treatment group.

Third, our study provides evidence for introducing an online peer group in addition to face-to-face counseling, as our experiment did not include a no-treatment control group. Thus, we cannot isolate the effects of participating in the online peer group and attending the face-to-face counseling sessions. Still, ethical and legal considerations do not support such a study design in our setting.

Finally, our case study is solely intended as a first step in examining the effect of online peer groups in the older unemployed population. In contrast to prior research, we observe that the increased job seeking activity of older unemployed individuals did not go along with elevated self-efficacy or self-assessed skills. Thus, we suggest future research to further expand our study's findings by investigating the underlying dynamics for the behavior changes in older unemployed individuals. In particular, researchers might investigate the factors influencing the observed activation effect in more detail. Future research might compare cohorts with a diverse educational or professional background, unemployment duration, or chat activity. Also, we invite future research to investigate the inner-workings of online peer groups, e.g., to identify specific moderation types that elevate success.

\section{Conclusion}

Improving labor market prospects for older people is a priority for policymakers around the world [5], in light of the rapid aging of the worldwide population $[5,6]$. To date, research and policy have focused on nondigital job search assistance for this target group [9, 5]. Our research is motivated by the desire to investigate whether ICT can serve the older unemployed population. To this end, we analyzed the effect of online peer groups on several indicators related to re-employment. We conducted the analysis using a unique online peer group data set from a randomized field study with unemployed individuals above the age of 50 at the Federal Employment Agency in Germany.

Our findings suggest that online peer groups can support older unemployed individuals. We observe that online peer groups activate participants and increase the number of job applications and job interviews. Our results further highlight that older unemployed individuals actively participate in online peer groups and thus support the call for a targeted design of digital interventions for this age group.

We hope our findings will encourage further investigation into the power of digital interventions to serve the older unemployed population.

\section{References}

[1] Klehe, U., J. Koen, and I.E. DePater, "Ending on the scrap heap: The experience of job loss and job search among older workers", in The Oxford handbook of work and aging, Oxford University Press, New York, 2012, pp. 313-340.

[2] A.T. Jebb, M. Morrison, L. Tay, and E. Diener, "Subjective Well-Being Around the World: Trends and Predictors Across the Life Span", Psychological Science, 31(3), 2020, pp. 293-305. 
[3] A. Tisch, "The employability of older job-seekers: Evidence from Germany", Journal of the Economics of Ageing, 6(C), 2015, pp. 102-112.

[4] S. Vansteenkiste, N. Deschacht, and L. Sels, "Why are unemployed aged fifty and over less likely to find a job? A decomposition analysis", Journal of Vocational Behavior, 90, 2015, pp. 55-65.

[5] OECD, "Working Better with Age", Paris, 2019, https://www.oecd.org/employment/working-better-withage-c4d4f66a-en.htm, accessed 6-30-2020.

[6] United Nations, "World Population Ageing 2019", New York, 2019 , https://www.un.org/en/development/desa/population/pu blications/pdf/ageing/WorldPopulationAgeing2019Report.pdf, accessed 6-30-2020.

[7] D. Card, J. Kluve, and A. Weber, "What Works? A Meta Analysis of Recent Active Labor Market Program Evaluations", Journal of the European Economic Association, 16(3), 2018, pp. 894-931.

[8] M. Biewen, B. Fitzenberger, A. Osikominu, and M. Waller, "Which Program for Whom? Evidence on the Comparative Effectiveness of Public Sponsored Training Programs in Germany", ZEW Discussion Paper No. 07042, Zentrum für Europäische Wirtschaftsforschung (ZEW), Mannheim, 2007.

[9] S. Liu, J.L. Huang, and M. Wang, "Effectiveness of Job Search Interventions: A Meta-Analytic Review", Psychological Bulletin, 140(4), 2014, pp. 1-33.

[10] N. Gürtzgen, A. Nolte, L. Pohlan, and G.J. van den Berg, "Do digital information technologies help unemployed job seekers find a job? Evidence from the Internet Expansion in Germany", IZA Discussion Paper No. 11555, Institute for the Study of Labor (IZA), Bonn, 2018.

[11] P. Kuhn and H. Mansour, "Is Internet Job Search Still Ineffective?", The Economic Journal, 124(581), 2014, pp. 1213-1233.

[12] R. Garg and R. Telang, "Role of Online Social Networks in Job Search by Unemployed Individuals", in 33rd International Conference on Information Systems (ICIS), Association for Information Systems, Orlando/Florida, 2012.

[13] A. Felgenhauer, S. Hieronimus, J. Klier, M. Klier, and L. Thiel, "Mobile Job Search Applications-New Pathway to Increase Youths' Job Application Efforts?", in 25th European Conference on Information Systems (ECIS), Association for Information Systems, Guimarães/Portugal, 2017.

[14] M. Belot, P. Kircher, and P. Muller, "Providing Advice to Jobseekers at Low Cost: An Experimental Study on Online Advice", Review of Economic Studies, 86(4), 2019, pp. 1411-1447.

[15] J. Klier, M. Klier, L. Thiel, and R. Agarwal, "Power of Mobile Peer Groups: A Design-Oriented Approach to Address Youth Unemployment", Management Information Systems, 36(1), 2019, pp. 158-193.

[16] Katz, A.H. and E.I. Bender, The strength in us: Self-help groups in the modern world, New Viewpoints, New York, 1976.

[17] T.K. Houston, L.A. Cooper, and D.E. Ford, "Internet support groups for depression: a 1-year prospective cohort study", American Journal of Psychiatry, 159(12), 2002, pp. 2062-2068.

[18] N.S. Coulson, "How do online patient support communities affect the experience of inflammatory bowel disease? An online survey", Journal of the Royal Society of Medicine Short Reports, 4, 2013, pp. 1-8.

[19] J.A. Cunningham, T. van Mierlo, and R. Fournier, "An online support group for problem drinkers: AlcoholHelpCenter.net", Patient Education and Counseling, 70(2), 2008, pp. 193-198.

[20] M. Ambrose, L. Murray, N.E. Handoyo, D. Tunggal, and N. Cooling, "Learning global health: a pilot study of an online collaborative intercultural peer group activity involving medical students in Australia and Indonesia", BMC Medical Education, 17(1), 2017, pp. 1-11.

[21] V.J. Roscigno, S. Mong, R. Byron, and G. Tester, "Age Discrimination, Social Closure and Employment", Social Forces, 86(1), 2007, pp. 313-334.

[22] C.R. Wanberg, L.M. Hough, and Z. Song, "Predictive Validity of a Multidisciplinary Model of Reemployment Success", Journal of Applied Psychology, 87(6), 2002, pp. 1100-1120.

[23] R.W. McQuaid, "Job search success and employability in local labor markets", The Annals of Regional Science, 40(2), 2006, pp. 407-421.

[24] R. Kanfer, T.M. Kantrowitz, and C.R. Wanberg, "Job search and employment: A personality-motivational analysis and meta-analytic review", Journal of Applied Psychology, 86(5), 2001, pp. 837-855.

[25] C. Schmidt, "Wirkungsorientierte Evaluation in der beruflichen Rehabilitation", IQPR Forschungsbericht Nr. 5, IQPR, Cologne, 2007.

[26] J.C. Rife and J.R. Belcher, "Social Support and Job Search Intensity Among Older Unemployed Workers: Implications for Employment Counselors", Journal of Employment Counseling, 30(3), 1993, pp. 98-107.

[27] M. Fugate, A.J. Kinicki, and B.E. Ashforth, "Employability: A psycho-social construct, its dimensions, and applications", Journal of Vocational Behavior, 65, 2004, pp. 14-38.

[28] T.J. Maurer, "Career-relevant learning and development, worker age, and beliefs about self-efficacy for development", Journal of Management, 27(2), 2001, pp. 123-140.

[29] United Nations, "E-Government Survey 2018: Gearing E-Government to support transformation towards sustainable and resilient societies", New York, 2018, https://www.unescap.org/sites/default/files/E-

Government\%20Survey\%202018_FINAL.pdf, accessed 7-14-2020.

[30] R.W. McQuaid, C. Lindsay, and M. Greig, “'Reconnecting' the Unemployed Information and communication technology and services for jobseekers in rural areas", Information, Communication \& Society, 7(3), 2004, pp. 364-388.

[31] J. Klier, M. Klier, K. Schäfer-Siebert, and I. Sigler, "\#JOBLESS \#OLDER \#DIGITAL - DIGITAL MEDIA USER TYPES OF THE OLDER UNEMPLOYED”, in 28th European Conference on Information Systems (ECIS), Association for Information Systems, An Online AIS Conference, 2020. 
[32] Suphan, A., M. Feuls, and C. Fieseler, Social media's potential in improving the mental well-being of the unemployed, in Exploring the Abyss of Inequalities, Springer, Berlin, Heidelberg, 2012, pp. 10-28.

[33] A. Morris, J. Goodman, and H. Brading, "Internet use and non-use: Views of older users", Universal Access in the Information Society, 6(1), 2007, pp. 43-57.

[34] R. Hill, L. Betts, and S. Gardner, "Empowerment and enablement through digital technology in the generation of the digital age", Computers in Human Behavior, 48, 2015, pp. 1-23.

[35] G. Briscese, V. Quinn, and G. Zanella, "Improving Job Search Skills: A Field Experiment on Online Employment Assistance", IZA Discussion Paper No. 13170, Institute for the Study of Labor (IZA), Bonn, 2020.

[36] B. Boockmann and T. Brändle, "Coaching, Counseling, Case-Working: Do They Help the Older Unemployed Out of Benefit Receipt and Back Into the Labor Market?", German Economic Review, 20(4), 2019, pp. e436-e468.

[37] D. Gray, "A job club for older job seekers: An experimental evaluation", Journals of Gerontology, 38(3), 1983, pp. 363-368.

[38] J.C. Rife and J.R. Belcher, “Assisting Unemployed Older Workers to Become Reemployed: An Experimental Evaluation", Research on Social Work Practice, 4(1), 1994, pp. 3-13.

[39] J. Huber, T. Muck, P. Maatz, B. Keck, P. Enders, I. Maatouk, and A. Ihrig, "Face-to-face vs. online peer support groups for prostate cancer: A cross-sectional comparison study", Journal of Cancer Survivorship, 12(1), 2018, pp. 1-9.

[40] N.S. Coulson, "Receiving social support online: An analysis of a computer-mediated support group for individuals living with irritable bowel syndrome", Cyberpsychology and Behavior, 8(6), 2005, pp. 580-584.

[41] W.P. Erchul and B.H. Raven, "Social power in school consultation: A contemporary view of French and Raven's bases of power model", Journal of School Psychology, 35(2), 1997, pp. 137-171.

[42] S. Goswami, F. Köbler, J.M. Leimeister, and H. Krcmar, "Using online social networking to enhance social connectedness and social support for the elderly", in 31st International Conference on Information Systems (ICIS), Association for Information Systems, St. Louis/MO, 2010.

[43] A. Felgenhauer, M. Förster, K. Kaufmann, J. Klier, and M. Klier, "Online Peer Groups - a Design-Oriented Approach To Addressing the Unemployment of People With Complex Barriers", in 27th European Conference on Information Systems (ECIS), Association for Information Systems, Stockholm/Uppsala, 2019.

[44] European Commission, "Regional Innovation Monitor Plus - Baden-Württemberg”, Brussels, 2020, https://ec.europa.eu/growth/tools-databases/regionalinnovation-monitor/base-profile/badenw\%C3\%BCrttemberg, accessed 1-10-2020.

[45] Federal Employment Agency, "Der Arbeitsmarkt 2019 in Baden-Württemberg”, $\quad$ Stuttgart, 2020, https://www.arbeitsagentur.de/vor-ort/rdbw/download/1533733892871.pdf, accessed 1-10-2020.

[46] European Union, "Digitale Kompetenzen - Raster Zur Selbstbeurteilung", Brussels, 2015, https://www.europass-info.de/fileadmin/user_upload/eur opass-info.de/PDF/Raster_Digitale_Kompetenzen.pdf, accessed 6-30-2020.

[47] W. Mittag and R. Schwarzer, "Interaction Of Employment Status And Self-Efficacy On Alcohol Consumption: A Two-Wave Study On Stressful Life Transitions", Psychology \& Health, 8(1), 1993, pp. 7787.

[48] N. Menold and K. Bogner, "Design of rating scales in questionnaires", GESIS Survey Guidelines, GESIS Leibniz Institute for the Social Sciences, Mannheim, 2016.

[49] P.M. Podsakoff, S.B. MacKenzie, and N.P. Podsakoff, "Sources of Method Bias in Social Science Research and Recommendations on How to Control It", Annual Review of Psychology, 63 (1), 2012, pp. 539-569.

[50] J.C. Rife, "Older unemployed women and job search activity: The role of social support", Journal of Women \& Aging, 7(3), 1995, pp. 55-68.

[51] M. Kleijnen, K. de Ruyter, and M. Wetzels, "An assessment of value creation in mobile service delivery and the moderating role of time consciousness", Journal of Retailing, 83(1), 2007, pp. 33-46.

[52] T.Y. Chung and Y.L. Chen, "Exchanging social support on online teacher groups: Relation to teacher selfefficacy", Telematics and Informatics, 35(5), 2018, pp. 1542-1552.

[53] A. Barak, M. Boniel-Nissim, and J. Suler, "Fostering empowerment in online support groups", Computers in Human Behavior, 24(5), 2008, pp. 1867-1883.

[54] Y.K. Bartlett and N.S. Coulson, "An investigation into the empowerment effects of using online support groups and how this affects health professional/patient communication", Patient Education and Counseling, 83(1), 2011, pp. 113-119.

[55] E.A. Sterrett, "Use of a Job Club to Increase SelfEfficacy: A Case Study of Return to Work", Journal of Employment Counseling, 35(2), 1998, pp. 69-78.

[56] T. Aalbers, M.A. Baars, and M.G. Rikkert, "Characteristics of effective Internet-mediated interventions to change lifestyle in people aged 50 and older: A systematic review", Ageing Research Reviews, 10(4), 2011, pp. 487-497.

[57] K.J. Topping, "Trends in peer learning", Educational psychology, 25(6), 2005, pp. 631-645.

[58] T. Van Mierlo, "The $1 \%$ rule in four digital health social networks: An observational study", Journal of Medical Internet Research, 16(2), 2014, pp. 1-9.

[59] M. Feuls, C. Fieseler, M. Meckel, and A. Suphan, "Being unemployed in the age of social media", New Media \& Society, 18(6), 2016, pp. 944-965.

[60] C.F. van Uden-Kraan, C.H.C. Drossaert, E. Taal, E.R. Seydel, and M.A.F.J. van de Laar, "Self-reported differences in empowerment between lurkers and posters in online patient support groups", Journal of Medical Internet Research, 10(2), 2008, pp. 1-10. 